\title{
Real time flood forecasting in the Upper Danube basin
}

\author{
Thomas Nester*, Jürgen Komma, Günter Blöschl \\ Institute of Hydraulic Engineering and Water Resources Management, Vienna University of Technology, Karlsplatz 13/222, A-1040, \\ Vienna, Austria. \\ * Corresponding author. E-mail: nester@hydro.tuwien.ac.at
}

\begin{abstract}
This paper reports on experience with developing the flood forecasting model for the Upper Danube basin and its operational use since 2006. The model system consists of hydrological and hydrodynamic components, and involves precipitation forecasts. The model parameters were estimated based on the dominant processes concept. Runoff data are assimilated in real time to update modelled soil moisture. An analysis of the model performance indicates $88 \%$ of the snow cover in the basin to be modelled correctly on more than $80 \%$ of the days. Runoff forecasting errors decrease with catchment area and increase with forecast lead time. The forecast ensemble spread is shown to be a meaningful indicator of the forecast uncertainty. During the 2013 flood, there was a tendency for the precipitation forecasts to underestimate event precipitation and for the runoff model to overestimate runoff generation which resulted in, overall, rather accurate runoff forecasts. It is suggested that the human forecaster plays an essential role in interpreting the model results and, if needed, adjusting them before issuing the forecasts to the general public.
\end{abstract}

Keywords: Hydrological model; Real time forecasting; Dominant processes; Data assimilation.

\section{INTRODUCTION}

The EU Flood Risk Directive (EU, 2007, p. 31) stipulates that "Flood risk management plans shall address all aspects of flood risk management focusing on prevention, protection, preparedness, including flood forecasts and early warning systems and taking into account the characteristics of the particular river basin or sub-basin." Local protection of buildings and early evacuation may be highly effective in complementing other flood management measures such as flood retention and raising the flood risk awareness of local citizens. For all of these measures reliable hydrological forecasts are needed.

In the Upper Danube basin several flood forecasting models are in operational use, eg., in Bavaria (Laurent et al., 2010; Vogelbacher, 2011), in Salzburg (Wiesenegger, 2006), Tyrol (Kirnbauer and Schönlaub, 2006; Schöber et al., 2010) and in Upper and Lower Austria (e.g., Blöschl et al., 2008, 2014). Further downstream the Danube, models are in use in Slovakia (Hlavcova et al., 2006), Hungary (Balint et al., 2006; Csík et al., 2007) and Romania (Matreata et al., 2013). The models are operated by the hydrological offices or dedicated forecasting services in each country or state, depending on the responsibilities assigned by the respective constitutions.

Floods in the Upper Danube basin in Austria are produced by a spectrum of different processes, including rain-on-snow and frontal precipitation. In order to account for these processes accurately when predicting large floods, a process based perspective is required. The forecasts are required over lead times of 48 hours with minimum biases including estimates of the forecast reliability. Specific data assimilation schemes are needed to meet these requirements.

The aim of this paper is to report on experiences made with developing the flood forecasting model for the Upper Danube basin and its operational use since 2006 that accounts for both these requirements - process based and specific assimilation procedures. The real time flood forecasting system is run by the state governments of Upper and Lower Austria and consists of meteorological forecasts covering the entire Upper Danube basin, hydrological forecasts in the tributaries and hydrodynamic forecasts for the Danube itself.
The paper is organised as follows. The Study region and data section gives details on the study area and the data used for calibrating and validating the model and data used for real time forecasting. The Hydrologic model section gives a short description of the hydrological model implemented in the model. In the Dominant processes concept section, the concept used for the calibration of the models is presented. The Forecasting and data assimilation section describes the way the model is used for operational forecasting and gives a brief overview of the data assimilation techniques implemented. The Model performance section gives a summary of (a) the model performance in a simulation mode, (b) of the snow routine of the model and (c) of the ensemble forecasts errors, followed by The value of ensemble forecasts section. The performance of the forecasts during the flood in June 2013 in the Upper Danube basin is presented in the next section. The final section discusses the results and concludes with remarks on conceptualising flood forecasting models.

\section{Study region and data}

The region which is covered by the real time runoff forecasting system covers large parts of Austria and some parts of Bavaria (Figure 1). Alpine regions with elevations of up to $3800 \mathrm{~m}$ a.s.l. are in the West of the region, prealpine areas and lowlands with elevations between 200 and $800 \mathrm{~m}$ a.s.l. can be found in the North and East. The region is hydrologically quite diverse with mean annual precipitation ranging from 600 $\mathrm{mm} / \mathrm{yr}$ in the East to almost $2000 \mathrm{~mm} / \mathrm{yr}$ in the West. As a consequence, annual runoff depths are higher in the Alpine catchments in the West (almost $1600 \mathrm{~mm} / \mathrm{yr}$ ) compared to the lowlands in the East (around $100 \mathrm{~mm} / \mathrm{yr}$ ). The catchment area of the Upper Danube Basin at the gauge Wildungsmauer (at the Eastern end of the Danube reach in Austria, see Figure 1) is about $104000 \mathrm{~km}^{2}$. Due to the large size of the Upper Danube basin the model domain was subdivided into catchments rather than pixels. There are 57 gauged catchments within the domain with sizes ranging from $70 \mathrm{~km}^{2}$ to $25600 \mathrm{~km}^{2}$ (median size around $400 \mathrm{~km}^{2}$ ). The catchments were further divided into elevation zones of 500 meters to better account for snow 


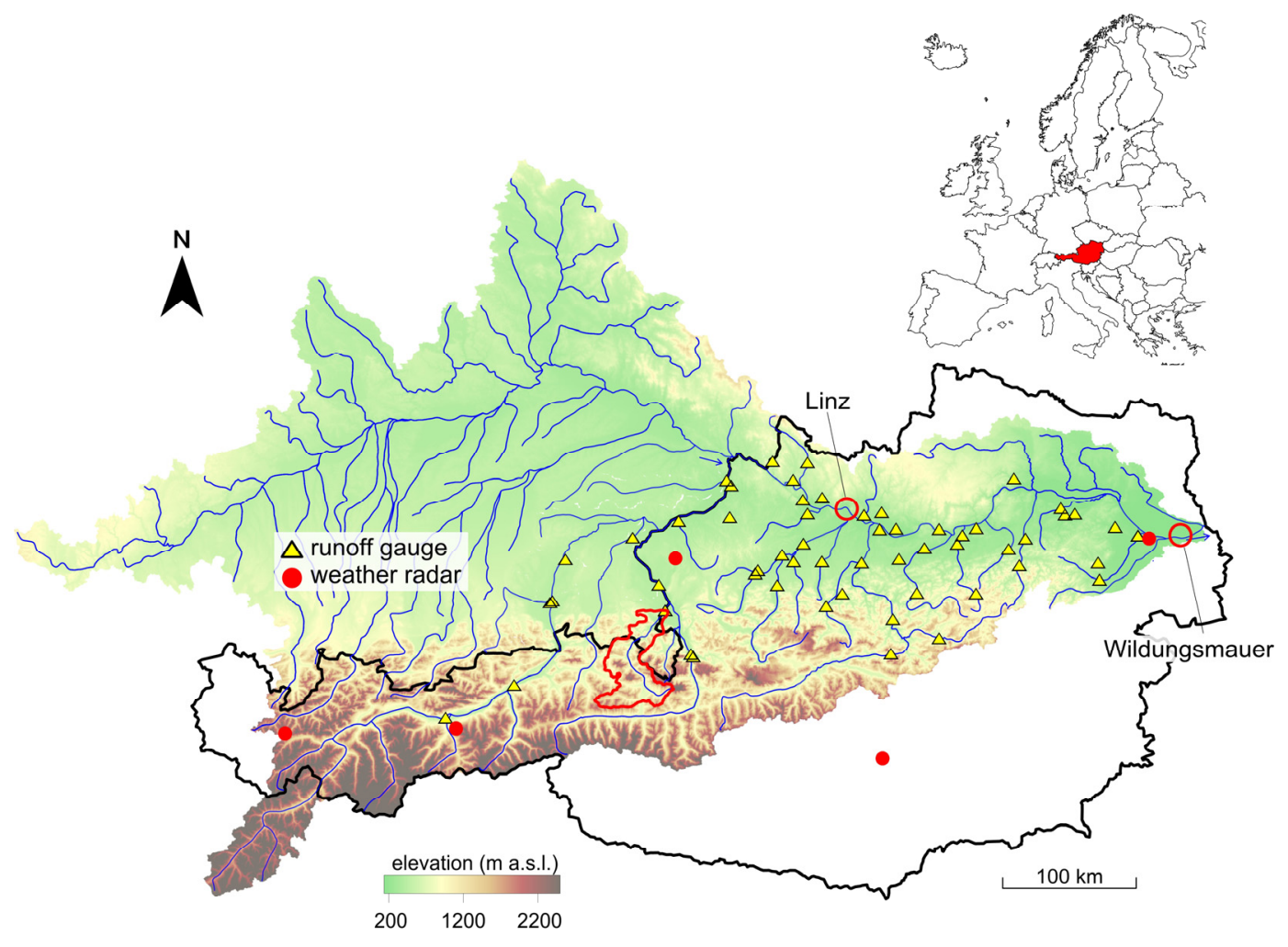

Fig. 1. Topography of the model domain in Austria and Southern Germany. The stream gauges for which flood forecasts are calculated are indicated by triangles, weather radar stations are indicated by red points. The catchment highlighted in red is Siezenheim/Saalach. Gauges Linz and Wildungsmauer are indicated by red circles. Redrawn after Nester et al. (2011).

accumulation and melt. Land use is mainly agricultural in the lowlands, forested in the medium elevation ranges and alpine vegetation, rocks and glaciers in the alpine catchments.

The model uses hourly values of precipitation, air temperature and potential evapotranspiration as inputs. For calibration, data from the years 2002 to 2009 were used. The first year was used as a warm-up period for the model, 2003-2006 was the calibration period and 2007-2009 was the validation period. Meteorological input data were provided by the Central Institute for Meteorology and Geodynamics (ZAMG) in Vienna. Rain gauge data were spatially interpolated on a $1 \mathrm{~km}$ grid and combined with radar data as a weighted mean for each time step (Haiden and Pistotnik, 2009; Haiden et al., 2011). The approach combines the accuracy of point measurements and the spatial structure of the radar field. However, two possible error sources need to be considered: (1) the rain gauge deficit of about $5 \%$ in summer and $10-20 \%$ in winter and (2) the interpolation errors which depend on the precipitation type (Viglione et al., 2010a, 2010b). The spatial distribution of potential evapotranspiration is estimated by a modified Blaney-Criddle equation (DVWK, 1996), which gives plausible results in Austria (Parajka et al., 2003). The gridded weather data fields were superimposed on the subcatchment boundaries to estimate hourly catchment average values. For air temperature and potential evapotranspiration, elevation was additionally accounted for by dividing all catchments into $500 \mathrm{~m}$ elevation zones.

To calibrate and verify the hydrological model, hourly discharge data from 57 stream gauges provided by the Hydrographical Service in Austria were used. The data were checked for errors (e.g., single hours with implausible high runoff values; sudden rises or drops in the runoff hydrograph) and in cases where a plausible correction could be made they were corrected. Otherwise they were marked as missing data.

\section{Hydrologic model}

The rainfall-runoff model used for real time flood forecasting in the Upper Danube basin is a typical conceptual hydrologic model (Blöschl et al., 2008; Komma et al., 2008). The structure of the model is similar to that of the HBV model (Bergström, 1976) but several adaptations (e.g., additional ground water storage, bypass flow) were made to account for the particular characteristics of the model domain (Blöschl et al., 2008; Komma et al., 2008). The model includes a snow routine, a soil moisture routine and a flow routing routine based on a linear storage cascade in the state space notation of Szolgay (2004). The temporal scale of the model is 1 hour, the spatial scale of the model are catchments divided into elevation zones. Figure 2 shows the model scheme used in each elevation zone in all catchments.

In the snow routine, snow accumulation and melt are represented by a simple degree-day concept, involving the degreeday factor $D\left(\mathrm{~mm}^{\circ} \mathrm{C}^{-1}\right.$ day $\left.^{-1}\right)$ and melt temperature $T_{m}\left({ }^{\circ} \mathrm{C}\right)$. A snow correction factor, $C_{S}(-)$ is used to correct the catch deficit of the precipitation gauges. If the air temperature $T_{a}\left({ }^{\circ} \mathrm{C}\right)$ is above a threshold temperature $T_{r}\left({ }^{\circ} \mathrm{C}\right)$, precipitation is considered to fall as rain; if $T_{a}\left({ }^{\circ} \mathrm{C}\right)$ is below a threshold temperature $T_{s}\left({ }^{\circ} \mathrm{C}\right)$, precipitation is considered to be snow and as a mix if $T_{a}\left({ }^{\circ} \mathrm{C}\right)$ is between $T_{r}\left({ }^{\circ} \mathrm{C}\right)$ and $T_{s}\left({ }^{\circ} \mathrm{C}\right)$.

Runoff generation and changes in soil moisture storage are represented in the soil moisture routine with three parameters: the maximum soil moisture storage $L_{S}(\mathrm{~mm})$, a parameter representing the soil moisture state above which evaporation is at its potential rate, termed the limit for potential evaporation $L_{P}$ $(\mathrm{mm})$, and a parameter in the nonlinear function relating runoff generation to the soil moisture state, termed the nonlinearity parameter $\beta(-)$. Runoff routing in the elevation zones is 




Fig. 2. Model scheme. Taken from Nester et al. (2011).

represented by three reservoirs: the upper and lower zones and a groundwater reservoir. Excess rainfall enters the upper zone reservoir and leaves this reservoir through three paths: outflow from the reservoir based on a fast storage coefficient $k_{l}(\mathrm{~h})$; percolation to the lower zone with a constant percolation rate $c p$ $\left(\mathrm{mm} /\right.$ day); and if a threshold of the storage state $\mathrm{L}_{1}(\mathrm{~mm})$ is exceeded, through an additional outlet controlled by a very fast storage coefficient $k_{0}(\mathrm{~h})$. Water leaves the lower zone based on a slow storage coefficient $k_{2}(\mathrm{~h}) . k_{3}(\mathrm{~h})$ controls the outflow from the groundwater storage. Additionally, a bypass flow $Q_{b y}(\mathrm{~mm})$ is introduced to account for precipitation that bypasses the soil matrix and directly contributes to the storage in the lower soil levels (Blöschl et al., 2008). Outflow from all reservoirs is then routed by a transfer function which consists of a linear storage cascade with the parameters $N$ (-; number of reservoirs) and $K$ ( $h$; time parameter of each reservoir).

\section{Dominant processes concept}

While large-scale meteorological models and satellites provide important inputs, in particular on future precipitation, capturing the local hydrological situation is essential for accurately modelling floods (Blöschl, 2008). Grayson and Blöschl (2000) referred to the notion of tailoring models to the local hydrological situation as the dominant processes concept (DPC) and noted: "Maybe instead of trying to capture everything when upscaling we should be developing methods to identify dominant processes that control hydrological response in different environments and scales, and then develop models to focus on these dominant processes" [p.366]. The idea can be straightforwardly applied at the hill slope scale and in small catchments. For example, Scherrer and Naef (2003) identified Hortonian overland flow, saturation excess flow, lateral subsurface flow and vertical subsurface flow on a $60 \mathrm{~m}^{2}$ hillslope. Blöschl et al. (2015) identified infiltration excess overland flow, re-infiltration of overland flow, saturation excess runoff from wetlands, tile drainage flow, shallow aquifer seepage flow and groundwater discharge from springs in the 66 ha Hydrological Open Air Laboratory (HOAL) in Lower Austria, and Rogger et al. (2012) classified runoff generation mechanisms by the hydrogeological characteristics through extensive field explorations in a $73 \mathrm{~km}^{2}$ catchment. In addition 
to the catchment properties, climatological and meteorological properties will also affect the dominant processes (e.g., Gutknecht, 1993, 1994; Merz and Blöschl, 2003; Sui and Koehler, 2001).

For larger catchments, application of the DPC is less straightforward. Reszler et al. (2008) adapted the DPC to larger catchment scales. They calibrated their pixel based hydrological forecasting system for the Kamp River (a $622 \mathrm{~km}^{2}$ catchment in Lower Austria) according to the dominant land use of the pixel. Reszler et al. (2008) used three different hydrological situations to verify their model parameters: (1) snow-induced floods, (2) convective events and (3) synoptic events.

As an example, Figure 3 shows surface runoff on a steep forested hillslope in the Kamp catchment after a synoptic event in 2005. Figure 4 shows the model results for two synoptic events in the Kamp catchment. Panel (a) shows precipitation and cumulative precipitation for two weeks in August 2005; panel (b) shows the corresponding simulated mean relative soil moisture; panel (c) shows the simulated mean storage depths of the soil reservoirs; and panel (d) shows the simulated and observed runoff at the stream gauge. Prior to the first event, soil moisture was low. The first rainfall increases soil moisture which soon leads to runoff production. After the first event, soil moisture is high and the precipitation on 20 and 21 August caused an even steeper rising limb of the runoff hydrograph.

As the catchment size increases, the parameter estimation needs to rely more on the runoff data and less on the field observations, as field surveys become less viable and part of the hydrological variability averages out (Sivapalan, 2003; Skøien and Blöschl, 2006). For the Danube basin, the dominant processes were therefore identified by a stepwise procedure (Blöschl, 2008). First, model parameters were adjusted in order to match the observed annual water balance. This was done by manually setting initial parameters for the snow routine, for

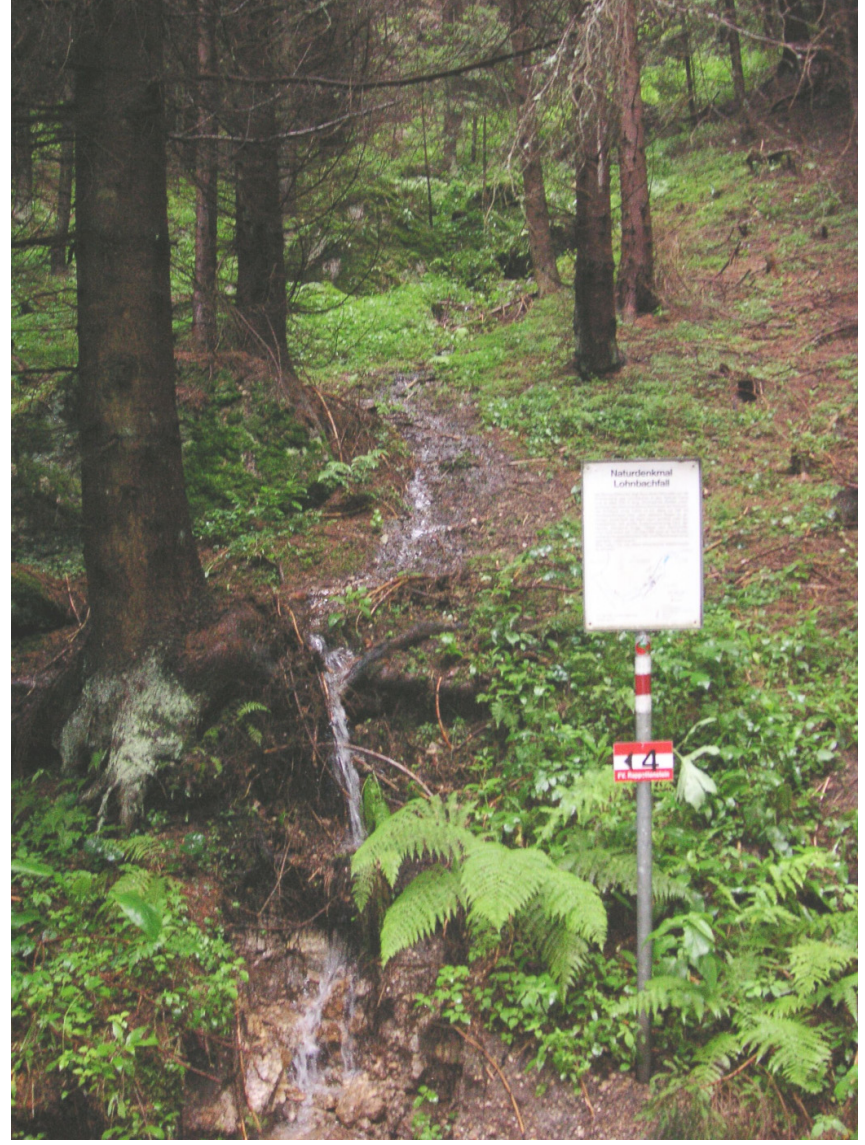

Fig. 3. Surface runoff on a steep forested hillslope in the Kamp region for an event in July 2005 which was a five year flood in the area. From Reszler et al. (2008).
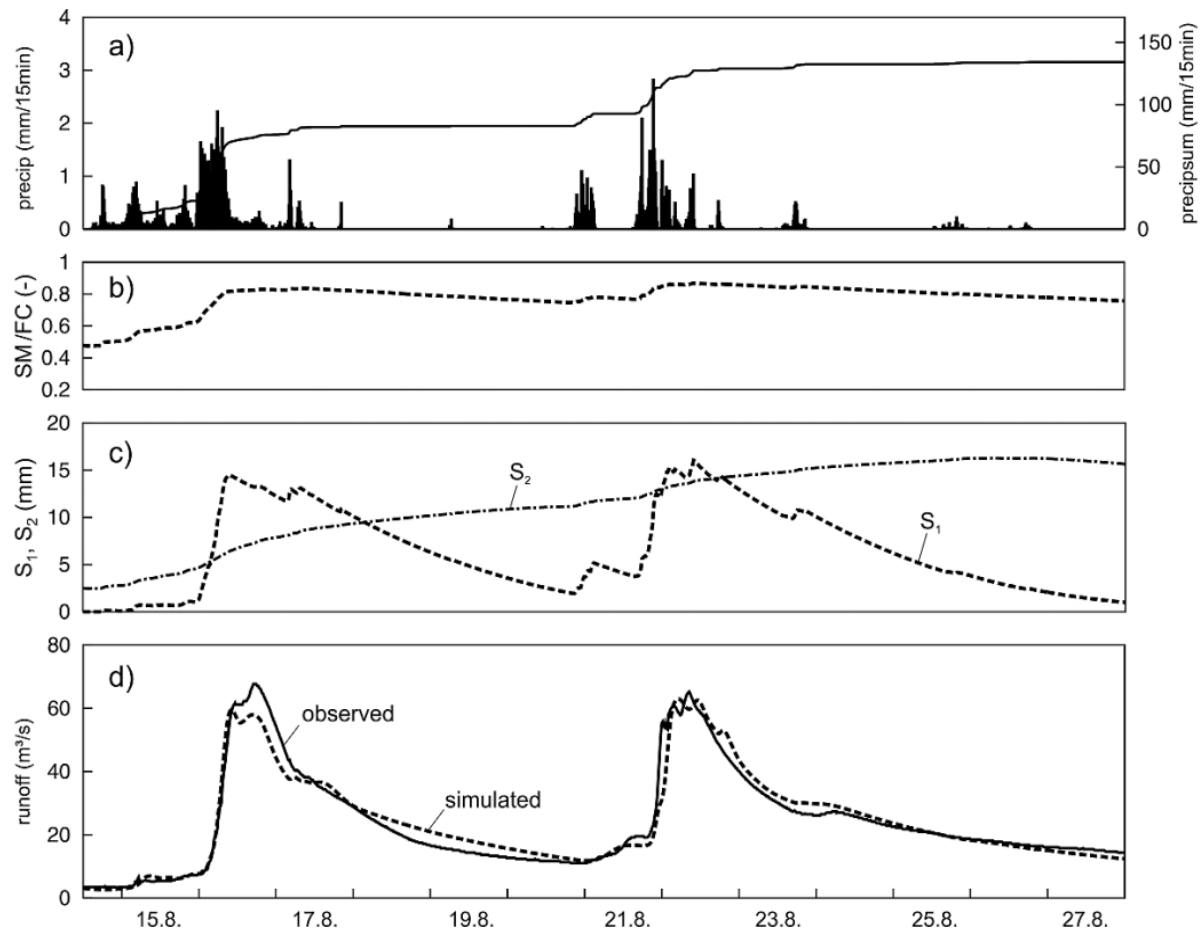

Fig. 4. Two synoptic events in the Zwettl/Kamp catchment in August 2005. (a) Precipitation and cumulative precipitation; (b) simulated mean relative soil moisture; (c) simulated mean storage depths of the soil reservoirs; (d) simulated and observed runoff at the stream gauge. After Reszler et al. (2008). 
the maximum soil moisture storage and for the slow runoff components based on the land use as in the Corine land cover data set (European Environment Agency, 2007). In a second step, the initial model parameters were adjusted to reproduce the observed seasonal patterns of the water balance component. Finally, the fast runoff components and parameters of the linear storage cascade were parameterized by analysing individual flood events on the basis of the slopes of the rising and receding limbs and the event peak of runoff.

\section{Forecasting and data assimilation}

The model is used in three different modes: (1) simulation mode for calibrating the model with observed meteorological data as inputs, (2) updating mode with observed meteorological and hydrological data as input and (3) real time forecasting mode.

During the calibration of the hydrologic model we ran simulations with quality checked data with no gaps in the data set for time periods of one year or longer and evaluated the model performance (for details, see, e.g., Nester et al., 2011).

In the real time mode, current system states such as water levels, snow cover and soil moisture contain information on the immediate future. In the updating mode, the model states are updating in order to increase the accuracy of the forecasts as new telemetered runoff data become available. Two real-time updating procedures are implemented in the model. The first is an Ensemble Kalman filter which assimilates runoff data to update catchment soil moisture (Komma et al., 2008). Uncertainties in the runoff measurements are interpreted as observation errors. The measurement error standard deviation was set to $5 \%$ of the measured runoff. Uncertainties in the rainfall inputs and evaporation (and their effect on soil moisture) are interpreted as model errors. The second procedure is an additive error model that exploits the autocorrelation of the forecast error and involves an exponential decay of the correction function (Komma et al., 2007).

For operational forecasting, the model uses hourly forecasts of precipitation (deterministic and Ensemble forecasts) and air temperature as inputs. At each forecasting time, the system states saved at the previous forecasting time are used as initial conditions. Deterministic forecasts of precipitation and temperature are generated over a lead time of 48 hours and consist of two components: the first component, termed nowcasts, is based on an extrapolation of the interpolated precipitation field using motion vectors (Steinheimer and Haiden, 2007). The second component is a weighted mean of the forecasts of the ALADIN and ECMWF numerical weather prediction (NWP) models. The two components are, again, combined as a weighted mean. To allow for a smooth transition between nowcasts and NWP results, the weights are varied as a function of lead time from full weight given to the nowcasts during the first 2 hours, full weight to the NWP forecasts after 6 hours, and a linear transition in between.

Ensemble forecasts have been used for quantifying and communicating the uncertainties of forecasts (see e.g., Demeritt et al., 2007; Hlavcova et al., 2006) using the spread of the ensemble members as a measure of forecast uncertainty (Buizza, 2003). To account for small scale spatial uncertainty, the ALADIN forecasts are spatially shifted in both West-East and North-South directions to produce 25 pseudo-ensembles. These pseudo-ensembles are randomly combined with 50 ensemble forecasts from the ECMWF model to generate Ensemble forecasts of precipitation. All ensemble members are identical up to a lead time of 2 hours (Komma et al., 2007) as no uncertainty is assigned to the nowcasts.

An important issue for the real time mode is the robustness and computational efficiency of the model. The model was set up in a way that it can be run even if part of the input data is missing. The model is also able to handle data errors and data transmission failures through dedicated filtering routines.

The flood forecasting system is operated by the state governments of Lower Austria and Upper Austria and has been in operational use for the Danube since 2006. The runoff forecasts of the hydrological model are routed through the Austrian Danube reach by a 1 dimensional hydrodynamic model (Reichel, 2001). Real time runoff forecasts are made publically available online on the homepages of the state governments of Upper Austria (http://www.landoberoesterreich.gv.at/was_internethydro.htm) and Lower Austria (http://www.noel.gv.at/Externeseiten/wasserstand/htm/ wndcms.htm).

\section{Model performance}

The performance of the model was tested in a number of ways, both for calibration and validation periods. The testing involved comparisons with observed runoff at annual, seasonal and event time scales as well as comparison with snow cover from satellite data (Nester et al., 2011, 2012a, 2012b). The model performance was found to mainly depend on the wetness of the catchments and the catchment size. For small catchments (area less than $400 \mathrm{~km}^{2}$ ) the Nash-Sutcliffe model efficiency (Nash and Sutcliffe, 1970) was, on average, 0.62, for medium sized catchments 0.67 and for large catchments (larger 1900 $\mathrm{km}^{2}$ ) 0.70. All of these performance measures are based on hourly simulations and are comparable with other studies (e.g., Das et al., 2008; Parajka et al., 2007).

Figure 5 gives an illustration of the performance of the snow routine of the model. The temporal evolution of snow covered area (SCA) estimated by the simulations was compared with SCA derived from MODIS satellite data. For $88 \%$ of the analysed area snow cover is modelled correctly on more than $80 \%$ of the days. Similarly, the timing of both the snow accumulation and depletion periods is simulated well. However, discrepancies between model and MODIS occur at the beginning and end of each snow season, when the snow cover is thin and patchy. The validation suggests that the model tends to somewhat underestimate snow cover in prealpine areas and forested areas while it has almost no bias in alpine catchments and open land.

The performance of the runoff ensemble forecasts for lead times up to 48 hours was analyzed for the period 2006-2009. The contributions of precipitation forecast error and hydrologic simulation error to the total forecast error was quantified and it was also examined whether the spread of the ensemble forecasts during floods captures these errors. The results show that all errors decrease very clearly with catchment area, although the rate of decrease differs with the error component and the lead time. The precipitation forecast errors (right panel in Figure 6) have the strongest decrease with catchment area, and they also decrease with decreasing lead time (from 48 to 12 hours). For lead times longer than the catchment response time, precipitation forecast errors will no longer affect the runoff forecasts. The hydrological simulation errors (centre panel in Figure 6) also decrease with catchment area due to aggregation effects. However, the dependence on the lead time is much weaker. The existing dependence of the errors on the lead time 


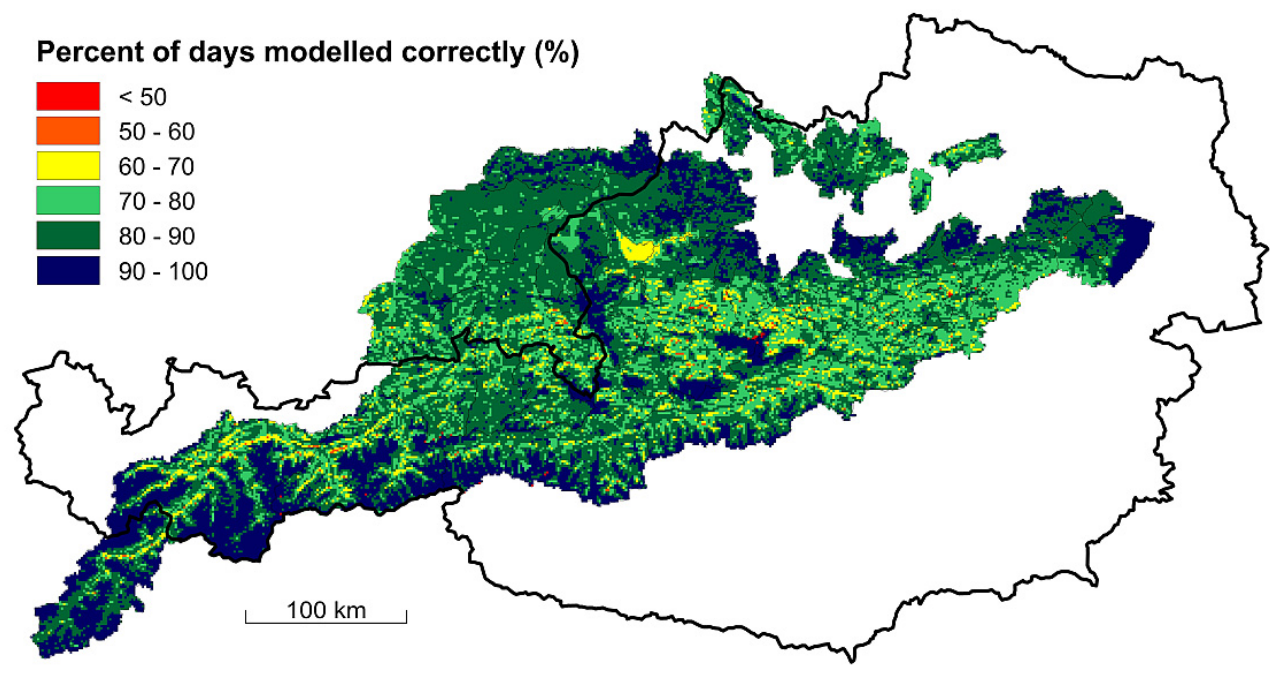

Fig. 5. Performance of the snow routine in the simulation mode for the period 2003-2009. A pixel is considered correctly modelled if both the model and MODIS satellite data indicate either snow or no snow. Dark blue pixels refer to the best performance of correct snow modelling on $90-100 \%$ of the days.


Fig. 6. Errors scaled by mean catchment runoff vs. catchment area for the largest $10 \%$ of ensemble spreads for 43 catchments. From left to right: Total forecast errors $\sigma_{\varepsilon}$, hydrologic simulation errors, $\sigma_{h y s i m}$, and precipitation forecast errors, $\sigma_{p f o r}$. The regression lines relate to different forecast lead times according to the grey scale. $(*)$ the hydrologic simulation error includes precipitation measurement and interpolation errors. From Nester et al. (2012b).

is related to the updating of the model (see Komma et al., 2008), while without updating (simulation mode) there is no dependence. The total forecast errors (left panel in Figure 6) are the combined results of the two error components. There is again a strong dependence on catchment area and a moderate dependence on the forecast lead time. Overall, the ensemble forecasts are capable of representing the total forecast error as a function of lead time well.

\section{The value of ensemble forecasts}

The value of ensemble forecasts is illustrated in Figure 7. The so called "range hit rates" is defined as the ability of ensemble flood forecasts to capture forecast errors. A range hit is counted when the observed discharge value is within the range of a certain number of discharge ensemble members (Komma et al., 2007). The quantile describes the number of ensemble members used to define the upper and lower range. If all en- semble members are considered, the quantile is $100 \%$; a quantile of $80 \%$ means that the highest $10 \%$ and the lowest $10 \%$ of the ensemble forecast values are not taken into account, i.e., a range hit is counted if the observed runoff is within the range covered by the remaining $80 \%$ of the ensemble. A quantile of $0 \%$ relates here to the deterministic forecast alone, i.e., a range hit is counted if the observed runoff is identical with the deterministic forecast within the numerical accuracy of 2 digits used here. The range hit rate indicates in how many cases, relative to the total number of forecasts, the observed discharge value lies within the range of the ensemble quantiles.

Figure 7 shows the results of an analysis of 5 large flood events in the Kamp catchment for different forecast lead times. The range hit rate increases with the quantiles for all lead times since wider uncertainty ranges more easily capture the observed runoff. The increase of the range hit rat is even stronger for quantiles larger than $60 \%$. Overall, the range hit rates are much smaller than the quantiles. If the ensemble forecasts captured all 

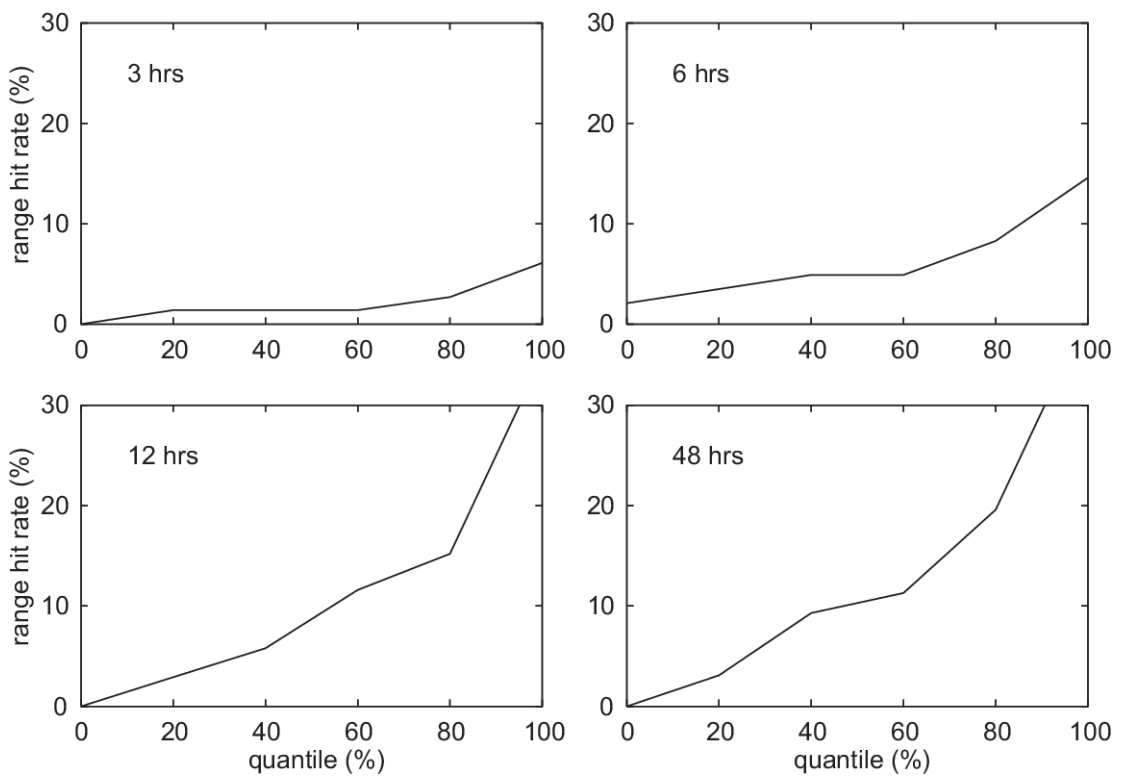

Fig. 7. Range hit rates during five flood events for lead times of 3,6, 12 and $48 \mathrm{~h}$ for the Kamp River at Zwettl, $622 \mathrm{~km}^{2}$. The range hit rate indicates in how many cases, relative to the total number of forecasts, the observed discharge value lies within the range of the ensemble quantiles. From Komma et al. (2007).

the forecast errors one would expect the range hit rates to lie on the 1:1 line in Figure 7. This is not the case as the ensemble forecasts focus on the dominant source of uncertainty, which is the uncertainty of the forecasted precipitation. Consequently, for short lead times, the range hit rates are always small as the errors of the routing model and the discharge measurements are not included. With increasing lead time, the precipitation forecast error becomes more important and the range hit rates increase. The range hit rates for the lead times of 12 and 48 hours are similar which suggests that the ensemble spread does provide a meaningful indicator of forecast errors over a range of lead times, provided the lead times are $12 \mathrm{~h}$ or larger.

\section{The June 2013 flood}

In June 2013, the Upper Danube basin was hit by one of the largest floods in the past two centuries. The flood was the first major flood event in the Upper Danube basin since the installation of the real time forecasting model by the Hydrographic Services in Upper and Lower Austria. The event is therefore a very realistic and independent test of for the accuracy of the forecasting system. In fact, the event was significantly larger than all the events in the calibration data set, so the evaluation also gives an indication of the ability of the model to extrapolate to larger events than those it was calibrated to.

Prior to the event, an extremely wet and colder than average month of May caused high soil moisture values in the catchment (BfG, 2013). There was a pronounced north-south gradient with higher soil moisture in the north, and lower soil moisture in the south. At the rain gauge in Lofer in the Salzach catchment, for example, $209 \mathrm{~mm}$ of precipitation were recorded in May 2013 (compared to the long-term May mean of $140 \mathrm{~mm}$ ). Also, ground water levels were high as indicated by numerous piezometers in the region. On 29 May, heavy precipitation started in the Northern part of the Danube catchment in Bavaria while in the South it started on 30 May and lasted until 2 June, 2013, with smaller precipitation intensities on the following two days. The recorded precipitation total in Lofer was $232 \mathrm{~mm}$ from 29 May to 4 June.
Figure 8 shows the spatial pattern of precipitation for a period of seven days (29 May to 4 June, 2013). As indicated in the figure, precipitation was highest along the northern ridge of the Alps in Austria (Tirol, Salzburg and Upper Austria) and there was also very significant precipitation further in the north. Precipitation interpolated between the rain gauges based on weather radar exceeded $300 \mathrm{~mm}$ during this time period. Precipitation was observed in two blocks separated by a few hours, resulting in a single peak, long-duration flood wave at the Inn and Danube. The small time lag between the two flood waves of the Bavarian Danube and the Inn exacerbated the downstream flood at the Danube. Maximum flood discharges of the Danube at Vienna were about $11000 \mathrm{~m}^{3} / \mathrm{s}$, as compared to 10 $300 \mathrm{~m}^{3} / \mathrm{s}$ in 2002 .

The propagation of the June 2013 flood along the stream network of the Upper Danube basin is shown in Figure 9. There were major contributions from the Isar (gauge Landshut) originating in the Alps. The Inn exhibited a much faster response as is always the case with this type of regional floods. The Upper Inn showed very little flood runoff and the flood wave built up through tributaries in Bavaria (gauge Wasserburg) and Salzburg (gauge Siezenheim). The flood wave of the Inn at Wasserburg merged with the Salzach wave, peaking essentially at the same time, and produced a very steep wave at Schärding with an estimated flood peak of about $5950 \mathrm{~m}^{3} / \mathrm{s}$, which represents an estimated return period of about 100 years. Upstream of Hofkirchen, a dam failure caused the water level to decrease and caused large inundations in the surroundings. The confluence of the Inn with the Bavarian Danube at Passau resulted in a characteristic, combined shape of the flood wave at Achleiten where the fast and slow contributions of Inn and Danube are clearly visible. The shape of the flood wave changed during the propagation along the Austrian Danube due to retention in the flood plains, which is apparent by the kink of the rising limb about a day before the peak. Inflow from southern tributaries along the Austrian reach of the Danube, including the Traun, Enns and Ybbs, gave rise to an early secondary peak, indicating that these tributaries peaked much earlier and hardly contributed to peak flows along the Danube. 




Fig. 8. Observed precipitation totals of the flood event in the Upper Danube Basin: 29 May 00:00 to 4 June 2013 24:00, based on rain gauge data and interpolated using radar data (Haiden et al., 2011). Red line indicates the Upper Danube catchment boundary above Wildungsmauer. From Blöschl et al. (2013).

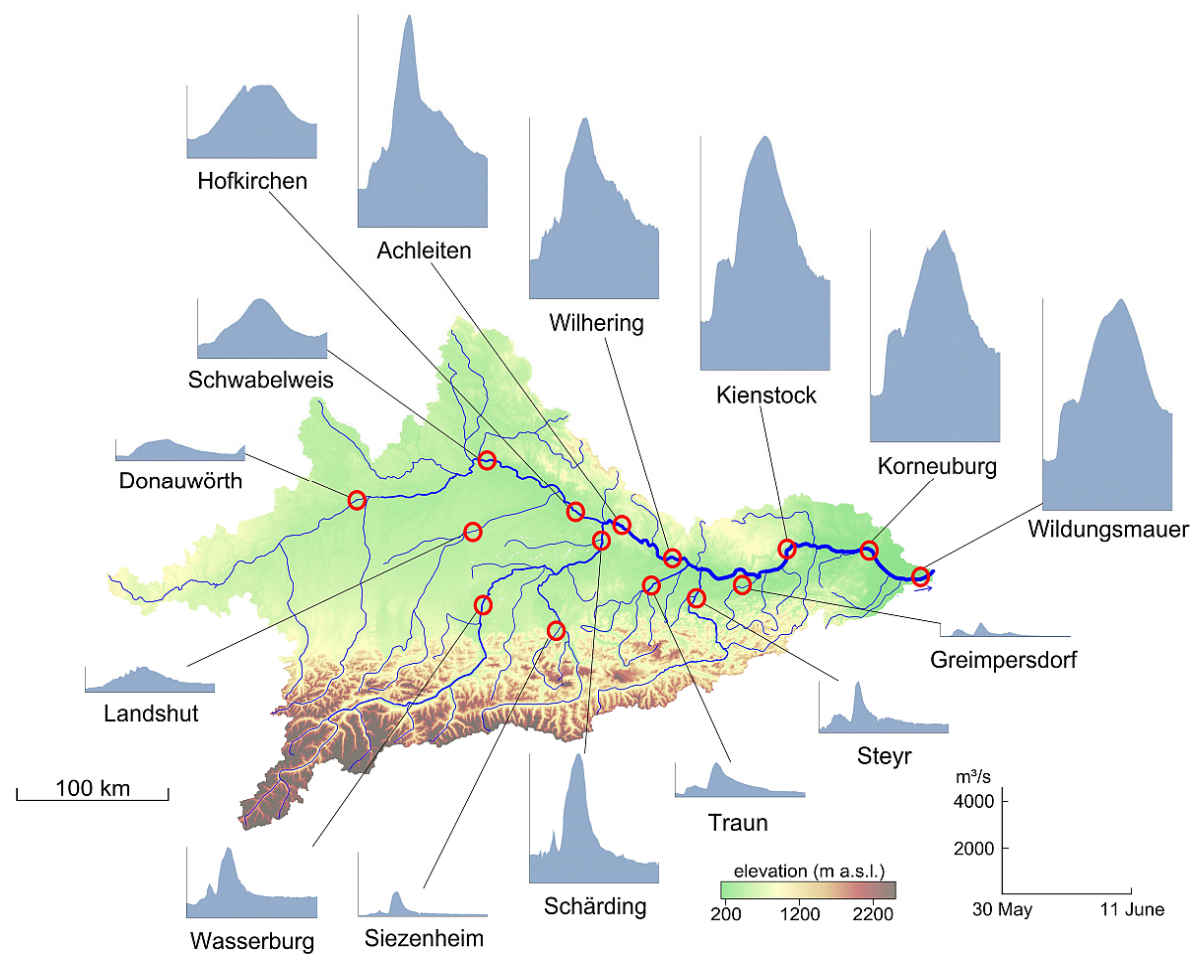

Fig. 9. Propagation of the June 2013 flood along the stream network of the Upper Danube Basin. Red circles indicate the stream gauges. The scale shown on the bottom right relates to all hydrographs (light blue areas). Modified after Blöschl et al. (2013).

Figure 10 shows the evolution of the meteorological and hydrological forecasts in the catchment Siezenheim for different lead times. Blue lines indicate observations, lines with points indicate forecasts. The panels (a) in the upper left corner show precipitation sums (moving window of 6 hours - in each precipitation panel) and forecasts of precipitation for a lead time of 6 hours, and observed and forecasted runoff, again for a lead time of 6 hours. The graphs show that the forecasts for a lead time of 6 hours match the observed precipitation well in regard to the precipitation total, but there is a time lag of about 3 hours. Consequently, the runoff forecasts lag behind about 3 hours. They overestimate the maximum observed runoff which is partly related to the parameters of the hydrological model and partly to a slight overestimation in the initial soil moisture. Given that there was no event of this magnitude in the calibration data set, the shape of the flood wave and the magnitude must be considered very good forecasts. Another issue that may have contributed to the overestimation was the breakdown of the data transmission from the stream gauges, so no data assimilation could be performed.

The panels (b) in the upper right corner show the results for a lead time of 12 hours. The timing error is slightly larger than for a 6 hour lead time and the magnitude of precipitation is significantly underestimated. One of the main reasons was the stationarity of the synoptic system which was not fully captured by the forecasts. As a result, the hydrological forecasts with a 

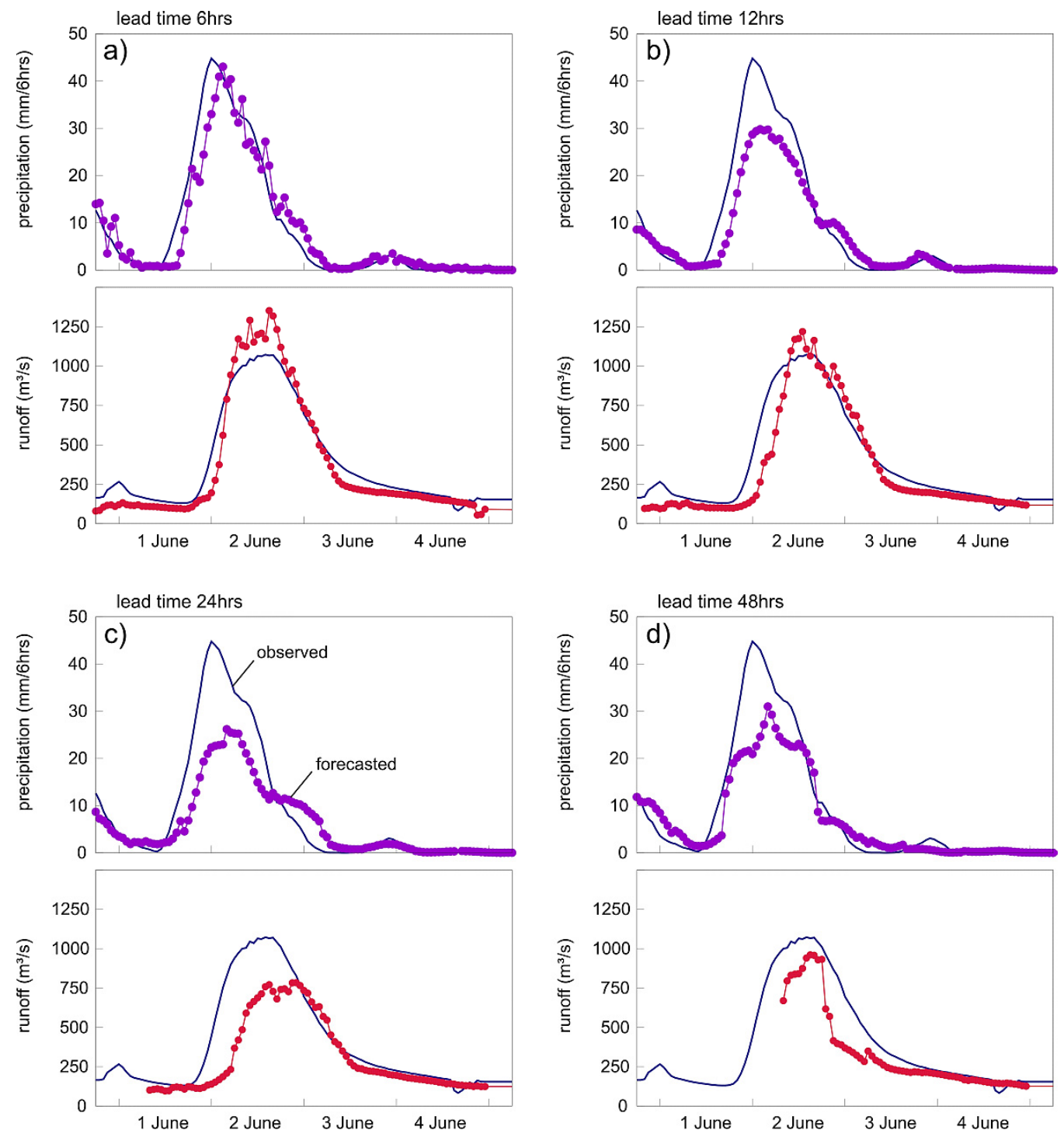

Fig. 10. Evolution of meteorological and hydrological forecasts during the June 2013 flood for the Siezenheim/Saalach catchment $\left(1118 \mathrm{~km}^{2}\right)$ at different lead times. Top panels show precipitation over moving windows of $6 \mathrm{~h}$, plotted at the end of that window (blue lines: observed, purple lines with points: forecasted precipitation). Bottom panels show runoff (blue lines: observed, red lines with points: forecasted runoff). The flood peak of $1100 \mathrm{~m}^{3} / \mathrm{s}$ was a 100 year flood at Siezenheim.

lead time of 12 hours have a larger timing error, however, the flood peak is only slightly overestimated. There is some compensation between the effects of underestimated precipitation and slightly overestimated runoff generation.

Panels (c) show the forecasts for a lead time of 24 hours. The precipitation forecasts again have a slightly larger time lag compared to the 12 hour forecasts, and the precipitation forecasts underestimate the observed precipitation by $20 \mathrm{~mm} / 6 \mathrm{hrs}$. This time lag and underestimation is reflected in the hydrological forecasts. Interestingly, for a lead time of 48 hours (panels (d)), the timing error is smaller although the forecasted precipitation is, again, significantly underestimated. The hydrological forecasts do match the observations rather well, in particular they have been correct in giving an early indication of the imminence of an extreme flood.

The results for Siezenheim are typical for the catchments with the highest precipitation intensities in the Upper Danube basin. In those catchments where intensities were lower, the deviations between the forecasts and the observations were smaller.

\section{CONCLUSIONS}

In this paper, we have reported on experiences with developing and operating the real time flood forecasting system in the Upper Danube basin. We have used the dominant processes concept in order to account for different processes that can lead to floods in the Upper Danube basin in Austria. A data assimilation scheme (Ensemble Kalman Filter) is used to increase the reliability of the forecasts.

The model is run on an hourly time step and the maximum forecast lead time is 48 hours. An analysis of the model performance suggests that the accuracy of the hydrological model forecasts increases with catchment area and decreases with forecast lead time. The latter finding is related to the uncertainty in the precipitation forecasts, as their importance increases with the lead time. The snow simulations were compared with MODIS satellite snow data indicating that $88 \%$ of the snow cover in the basin is modelled correctly on more than $80 \%$ of the days. Ensembles of precipitation are used to calculate ensembles of runoff forecast. The analysis shows that the ensemble spread is a meaningful indicator of the forecast uncertainty. 
The model has been in operational use since 2006. In June 2013, one of the biggest floods in the last two centuries occurred in the Upper Danube basin. The analysis of the performance of the model for this event is therefore a fully independent test of its forecast accuracy and its ability to extrapolate to events that are much larger than those in the calibration data set. The analysis suggests that, in many catchments, the model predicted runoff reliably, however, in some catchments the model overestimated runoff. This was partly related to the parameters of the hydrological model and partly to a slight overestimation of the initial soil moisture. It is noted that extrapolation to large events is always a challenge in hydrology. There is therefore an important role for the human forecasters in interpreting the model results and, if needed, adjusting them before issuing the forecasts to the general public.

\section{REFERENCES}

Balint, G., Csik, A., Bartha, P., Gauzer, B., Bonta, I., 2006. Application of meterological ensembles for Danube flood forecasting and warning. In: Marsalek, J., Stancalie, G., Balint, G. (Eds.): Transboundary Floods: Reducing Risks through Flood Management. Springer, NATO Science Series, Dordecht, The Netherlands, pp. 57-68.

Bergström, S., 1976. Development and application of a conceptual runoff model for Scandinavian catchments. Dept. Water Resour. Engng, Lund Inst. Technol./Univ. Lund, Bull. Ser. A52, 134.

BfG, 2013. Das Juni-Hochwasser des Jahres 2013 in Deutschland (The 2013 June flood in Germany), BfG Report no. 1793, Federal Institute of Hydrology, Koblenz, Germany.

Blöschl, G., Reszler, C., Komma, J., 2008. A spatially distributed flash flood forecasting model. Environ. Modell. Softw., 23, 4, 464-478.

Blöschl, G., 2008. Flood warning - on the value of local information. International Journal of River Basin Management, 6, $1,41-50$.

Blöschl, G., Nester, T., Komma, J., Parajka, J., Perdigão, R.A.P., 2013. The June 2013 flood in the Upper Danube basin, and comparisons with the 2002, 1954 and 1899 floods. Hydrology and Earth System Sciences, 17, 5197-5212.

Blöschl, G., Nester, T., Parajka J., Komma, J., 2014. Hochwasserprognosen an der österreichischen Donau und Datenassimilation. [Flood forecasting on the Austrian Danube and data assimilation]. Hydrologie und Wasserbewirtschaftung 58, 2, 64-72. doi: 10.5675/HyWa_2014,2_1. (In German.)

Blöschl, G., Blaschke, A. P., Broer, M., Bucher, C., Carr, G., Chen, X., Eder, A., Exner-Kittridge, M., Farnleitner, A., Flores-Orozco, A., Haas, P., Hogan, P., Amiri, A.K., Oismüller, M., Parajka, J., Silasari, R., Stadler, P., Strauß, P., Vreugdenhil, M., Wagner, W., 2015. The Hydrological Open Air Laboratory (HOAL) in Petzenkirchen: a hypotheses driven observatory. Hydrology \& Earth System Sciences Discussions, 12, 7, 6683-6753.

Buizza, R., Houtekamer, P.L., Toth, Z., Pellerin, G., Wei, M., Zhu, Y., 2005. A comparison of the ECMWF, MSC, and NCEP global ensemble prediction systems. Mon. Weather Rev., 133, 5, 1076-1097.

Csík, A., Bálint, G., Bartha, P., Gauzer, B., 2007. Application of meteorological ensembles for Danube flood forecasting and warning. In: Thielen, J., Bartholmes, J., Schaake, J., (Eds.): Abstracts of the 3rd HEPEX Workshop, Stresa, Italy, 27-29th June 2007. European Commission, Institute for Environment and Sustainability, EUR22861 EN.
Das, T., Bárdossy, A., Zehe, E., He, Y., 2008. Comparison of conceptual model performance using different representations of spatial variability. J. Hydrol., 356, 106-118.

Demeritt, D., Cloke, H.L., Pappenberger, F., Thielen, J., Bartholmes, J., Ramos, M.H., 2007. Ensemble predictions and perceptions of risk, uncertainty, and error in flood forecasting. Environmental Hazards, 7, 2, 115-127. doi:10.1016/j.envhaz.2007.05.001.

DVWK, 1996. Ermittlung der Verdunstung von Land- und Wasserflächen. [Estimation of the evaporation of land and water surfaces]. DVWK Merkblätter, Heft 238, Bonn. (In German.)

European Environment Agency, 2007. CLC2006 technical guidelines. Technical Report 17/2007, European Environment Agency. http://www.eea.europa.eu/publications/technical_report_200 7 17/at download/file.

EU, 2007. Directive 2007/60/EC of the European Parliament and the Council of 23 October 2007 on the assessment and management of flood risks. Off. J. Eur. Union, L288/27L288/34.

Grayson, R.B., Blöschl, G., 2000. Summary of pattern comparison and concluding remarks. Chapter 14. In: Grayson, R., Blöschl, G. (Eds.): Spatial Patterns in Catchment Hydrology: Observations and Modelling. Cambridge University Press, Cambridge, UK, pp. 355-367.

Gutknecht, D., 1993. Grundphänomene hydrologischer Prozesse. [Basic phenomena of hydrological processes]. Zürcher Geographische Schriften 53, ETH Zürich, pp. 25-38.

Gutknecht, D., 1994. Extremhochwässer in kleinen Einzugsgebieten. [Extreme floods in small catchments]. Österr. Wasser- und Abfallwirtschaft, 46, Heft 3/4, 50.57.

Haiden, T., Pistotnik, G., 2009. Intensity-dependent parameterization of elevation effects in precipitation analysis. Adv. Geosci., 20, 33-38, www.adv-geosci.net/20/33/2009/

Haiden, T., Kann, A., Wittmann, C., Pistotnik, G., Bica, B., Gruber, C., 2011. The Integrated Nowcasting through Comprehensive Analysis (INCA) System and its Validation over the Eastern Alpine Region. Weather Forecasting, 26, 166183. doi: 10.1175/2010WAF2222451.1

Hlavcova, K., Szolgay, J., Kubes, R., Kohnova, S., Zvolensky, M., 2006. Routing of numerical weather predictions through a rainfall-runoff model. In: Marsalek, J., Stancalie, G., Balint, G. (Eds): Transboundary Floods: Reducing Risks through Flood Management. NATO Science Series: IV: Earth and Environmental Sciences, Springer, Dordrecht, The Netherlands, pp. 79-90. doi:10.1007/1-4020-4902-1 8 .

Kirnbauer, R., Schönlaub, H., 2006. Vorhersage für den Inn. [Forecasts on the Inn River]. Wiener Mitteilungen, 199, 6984. (In German.)

Komma, J., Reszler, C., Blöschl, G., Haiden, T., 2007. Ensemble prediction of floods - catchment non-linearity and forecast probabilities. Nat. Hazards Earth Sys. Sci., 7, 431-444. doi: 10.5194/nhess-7-431-2007.

Komma, J., Blöschl, G., Reszler, C., 2008. Soil moisture updating by Ensemble Kalman Filtering in real-time flood forecasting. J. Hydrol., 357, 228-242.

Laurent, S., Hangen-Brodersen, C., Ehret, U., Meyer, I., Moritz, K., Vogelbacher, A., Holle, F.-K., 2010. Forecast uncertainties in the operational flood forecasting of the Bavarian Danube catchment. In: Brilly, M. (Ed.): Hydrological Processes of the Danube River Basin. Springer, Dordrecht, pp. 367-387.

Matreata, S., Baciu, O., Apostu, D., Matreata, M., 2013. Evaluation of the Romanian flash flood forecasting system - case 
study in the Calnau river basin. Die Bodenkultur, 64, 3-4, 2013.

Merz, R., Blöschl, G., 2003. A process typology of regional floods. Water Resources Research, 39, 12, 1340. doi:10.1029/2002WR001952, 2003

Nash, J.E., Sutcliffe, J.V., 1970. River flow forecasting through conceptual models: Part I. A discussion of principles. J. Hydrol., 10, 282-290. doi: 10.1016/0022-1694(70)90255-6.

Nester, T., Kirnbauer, R., Gutknecht, D., Blöschl, G., 2011. Climate and catchment controls on the performance of regional flood simulations. J. Hydrol., 402, 340-356, doi:10.1016/j.jhydrol.2011.03.028.

Nester, T., Kirnbauer, R., Parajka, J., Blöschl, G., 2012a. Evaluating the snow component of a flood forecasting model. Hydrology Research, 43, 762-779.

Nester, T., Komma, J., Viglione A., Blöschl, G., 2012b. Flood forecast errors and ensemble spread - a case study, Water Resources Research, 48, W10502, 19 p. doi: 10.1029/2011WR011649.

Parajka, J., Merz, R., Blöschl, G., 2003. Estimation of daily potential evapotranspiration for regional water balance modeling in Austria. In: 11th International Poster Day and Institute of Hydrology Open Day "Transport of Water, Chemicals and Energy in the Soil - Crop Canopy - Atmosphere System". Slovak Academy of Sciences, Bratislava, pp. 299-306.

Parajka, J., Merz, R., Blöschl, G., 2007. Uncertainty and multiple objective calibration in regional water balance modeling - Case study in 320 Austrian catchments. Hydrological Processes, 21, 435-446.

Reichel, G., 2001. Flux ${ }^{\text {DSS }}$ und FLORIS ${ }^{2000}$ - ein leistungsfähiges Paket zur Modellierung der Fließvorgänge in komplexen Systemen. [FluxDSS and FLORIS2000 - an efficient tool for modelling flow processes in complex systems]. Österreichische Wasserwirtschaft, 53, 5-6, 170-171.

Reszler, C., Komma, J., Blöschl, G., Gutknecht, D., 2008. Dominante Prozesse und Ereignistypen zur Plausibilisierung flächendetaillierter Niederschlag-Abflussmodelle. [Dominant processes and event types for checking the plausibility of spatially distributed runoff models]. Hydrologie und Wasserbewirtschaftung, 52, 3, 120-131. (In German.)

Rogger, M., Pirk1, H., Viglione, A., Komma, J., Kohl, B., Kirnbauer, R., Merz, R., Blöschl, G., 2012. Step changes in the flood frequency curve: Process controls. Water Resour. Res., 48, W05544. doi: 10.1029/2011WR011187.

Scherrer, S., Naef, F., 2003. A decision scheme to indicate dominant hydrological flow processes on temperate grassland. Hydrol. Process., 17, 391-401. doi:10.1002/hyp.1131.

Schöber, J., Achleitner, S., Kirnbauer, R., Schöberl, F., Schönlaub, H., 2010. Hydrological modelling of glacierized catchments focussing on the validation of simulated snow patterns - applications within the flood forecasting system of the Tyrolean river Inn. Adv. Geosci., 27, 99-109. doi: 10.5194/adgeo-27-99-2010.

Sivapalan, M., 2003. Process complexity at hillslope scale, process simplicity at the watershed scale: is there a connection? Hydrol. Process., 17, 1037-1041.

Skøien, J.O., Blöschl, G., 2006. Sampling scale effects in random fields and implications for environmental monitoring. Environ. Monit. Assess., 114, 1-3, 521-552.

Steinheimer, M., Haiden, T., 2007. Improved nowcasting of precipitation based on convective analysis fields. Adv. Geosci., 10, 125-131.

Sui, J., Koehler, G., 2001. Rain-on-snow induced flood events in Southern Germany, J. Hydrol., 252, 205-220.

Szolgay, J., 2004. Multilinear flood routing using variable travel-time discharge relationships on the Hron river. J. Hydrol. Hydromech., 52, 4, 303-316.

Viglione, A., Chirico, G.B., Komma, J., Woods, R., Borga, M., Blöschl, G., 2010a. Quantifying space-time dynamics of flood event types. J. Hydrol., 394, 1-2, 213-229. doi:10.1016/j.jhydrol.2010.05.041.

Viglione, A., Chirico, G.B., Woods, R., Blöschl, G., $2010 \mathrm{~b}$. Generalised synthesis of space-time variability in flood response: an analytical framework. J. Hydrol., 394, 1-2, 198212. doi: 10.1016/j.jhydrol.2010.05.047.

Vogelbacher, A., 2011. Flood warning in Bavaria, Germany. In: Proceedings of Environmental Knowledge for Disaster Risk Management, 10-11 May, 2011, New Delhi, India.

Wiesenegger, H., 2006. Hydris - Vorhersagen an der Salzach. [Hydris - forecasts on the Salzach River]. Wiener Mitteilungen, 199, 69-84. (In German.)

Received 1 December 2015 Accepted 17 May 2016 